\title{
Epidemiological Evaluation of Pediatric Elbow Injuries: A Retrospective Observational Single Center
}

\author{
Towseef Ahmad Bhat ${ }^{1}$ Manik Sehgal ${ }^{10}$ Rajiv Kapila ${ }^{2}$ Rubinder Kaur ${ }^{3}$ Rajan Singh Negi ${ }^{2}$ \\ ${ }^{1}$ Department of Orthopaedics, Pt. Jawahar Lal Nehru Government \\ Medical College and Hospital, Chamba, Himachal Pradesh, India \\ 2 Department of Orthopaedics, Dr. Rajendra Prasad Government \\ Medical College, Kangra, Tanda, Himachal Pradesh, India \\ ${ }^{3}$ Department of Anesthesia, Sri Guru Ram Das Medical College, \\ Vallah, Amritsar, Punjab, India \\ Address for correspondence Manik Sehgal, MBBS, MS, B 774 \\ New Amritsar, Amritsar, Punjab, India \\ (e-mail: Maniksehgal2001@gmail.com). \\ Int J Recent Surg Med Sci 2022;8:49-53.
}

\begin{abstract}
Introduction Elbow fractures are the commonest fractures in the pediatric age group. The aim of this study is to evaluate the epidemiology of fresh and neglected pediatric elbow fractures in a hilly state of India with a limited health care facility. Materials and Methods This was a retrospective observational single-center study conducted between January 2019 and January 2021.

Results Supracondylar was the most common fracture in $58.7 \%$ of patients followed by lateral condyle and proximal radius fracture. The highest number of fractures were reported in the age group of 5 to 8 years. In addition, $19 \%$ of patients presented with associated complications, $8 \%$ of patients had combination injuries of the ipsilateral

\section{Keywords}

- elbow

- pediatric

- fracture

- supracondylar upper limb, $16 \%$ of patients presented to the hospital 1 week after the trauma, $48 \%$ of patients had the first contact with a bonesetter/native practitioner.

Conclusion Supracondylar fracture was the most common elbow fracture followed by lateral condyle. The most common involved age group was 5 to 8 years. A significant number of elbow fractures are mismanaged by native practitioners in rural India.
\end{abstract}

\section{Introduction}

With $32.8 \%$ of 1.3 billion people in the pediatric age group in India, pediatric injuries constitute a major part of patients in trauma centers. ${ }^{1}$ Among the pediatric musculoskeletal injuries, elbow fractures are the most common. ${ }^{2}$ The exact incidence of pediatric elbow fractures is not known in India. Pediatric elbow injuries are usually caused by low-energy trauma such as tumble and fall, fall from a height on an outstretched hand, or during contact supports. However, elbow injuries are prone to complications such as compartment syndrome, neurovascular injury, malunion, stiffness, and myositis ossificans. Pediatric elbow fractures also have a small window period for surgery to get good functional outcome. ${ }^{3}$ In rural India, a significant number of low-energy elbow fractures get mismanaged or neglected due to lack of specialist orthopaedic facilities.

\section{Materials and Methods}

Complete epidemiological data on age at the time of injury, gender, the calendar month of injury, type of fracture (open/closed, single/combined, and unilateral/bilateral), fracture mechanism, combination injury of ipsilateral or contralateral upper limbs, and injury associated with acute
DOI https://doi.org/ 10.1055/s-0041-1736447. ISSN 2455-7420. (c) 2021. Medical and Surgical Update Society. All rights reserved. This is an open access article published by Thieme under the terms of the Creative Commons Attribution-NonDerivative-NonCommercial-License, permitting copying and reproduction so long as the original work is given appropriate credit. Contents may not be used for commercial purposes, or adapted, remixed, transformed or built upon. (https://creativecommons.org/ licenses/by-nc-nd/4.0/)

Thieme Medical and Scientific Publishers Pvt. Ltd., A-12, 2nd Floor, Sector 2, Noida-201301 UP, India 
complications such as neurovascular injury or compartment syndrome were obtained and recorded.

We classified the patients into four age groups 1 to 4 years (including up to 1 year old), 5 to 8 years, 9 to 12 years, and 12 to 15 years. To understand the mode of trauma we used the following categories.

1. Fall on plane/level ground on an outstretched hand.

2. Fall from a height on an outstretched hand.

3. Direct trauma/hit.

4. Twisting injury during sports/sports injury.

5. Road traffic accident (RTA).

On the basis of presentation, we classified the patients into three groups: (1) Within 48 hours; (2) between 48 hours to 7 days; (3) after 7 days.

\section{Results}

Out of 211 patients, 135 were boys and 76 were girls, resulting in elbow fractures 1.7 times more in boys.

In total, 129 fractures were on the left side and 82 were on the right side, resulting in a right/left ratio of 0.6 . No patient had a bilateral injury. Eleven patients (5.2\%) had open fractures.

Forty (19\%) patients presented with associated complications such as gross swelling with blister formation, cellulitis, compartment syndrome, or neurovascular injury. The management of such cases was decided on the basis of presentation. Patients with gross swelling, blister formation, and cellulitis needed prolonged observation in the hospital. All patients with associated complications had a history of manipulation by a bonesetter. Fourteen (6.6\%) patients had a combination injury of the ipsilateral side. Most of the patients, (102 [48\%]) presented more than 48 hours after the trauma, and 37 (16\%) patients with elbow fractures presented more than 7 days after the trauma. In addition, 102 (48\%) patients had first contacted a bonesetter before coming to the hospital (-Table $\mathbf{1}$ ).

A significant seasonal variation was observed in our study with the most number of cases in the summer season (between April to September). The highest number of cases (40) was seen in June and the least in January (-Fig. 1).

The most common age group was between 5 and 8 years and the most frequent year was the fifth year of age ( $\mathbf{F i g . ~ 2 A , B ) . ~}$

The most common mechanism of injury (49\%) was a fall from a height on an outstretched hand followed by a fall on outreached hand on level ground. In the age group of 1 to 4 years, fall on level ground was the most common mode of injury. Sports injuries and road traffic accidents as the mode of trauma were reported (-Table 2 ).

Supracondylar (SC) fractures constituted $58.7 \%$ of all elbow fractures. Gartland type III was the most common fracture, ${ }^{4}$ and $4.8 \%$ of patients had open SC fractures. Sixteen supracondylar fractures presented with gross swelling around the elbow with a pink pulseless warm hand. Three patients presented with cold pulseless limbs and were referred for vascular surgery intervention. Eleven patients had associated bony injury of ipsilateral limb, and 1 patient
Table 1 Parameters of pediatric elbow fractures

\begin{tabular}{|l|l|}
\hline Parameter & Number, $\mathbf{n}(\%)$ \\
\hline Total no of patients & 211 \\
\hline Gender & \\
\hline Male & $135(64)$ \\
\hline Female & $76(36)$ \\
\hline Laterality & \\
\hline Right & $82(38)$ \\
\hline Left & $129(62)$ \\
\hline Bilateral & 0 \\
\hline Open fractures & $11(5.2)$ \\
\hline Closed fractures & $200(94.8)$ \\
\hline Fractures with complications & $40(19)$ \\
\hline Combination fractures & $14(6.6)$ \\
\hline Presentation & \\
\hline Within 48 h & $82(34)$ \\
\hline 48 h to 7 d & $102(48)$ \\
\hline After 7 d & $37(18)$ \\
\hline $\begin{array}{l}\text { Patients having the first contact } \\
\text { with bonesetter }\end{array}$ & $102(48)$ \\
\hline
\end{tabular}

Abbreviations: $n$, number of patients.

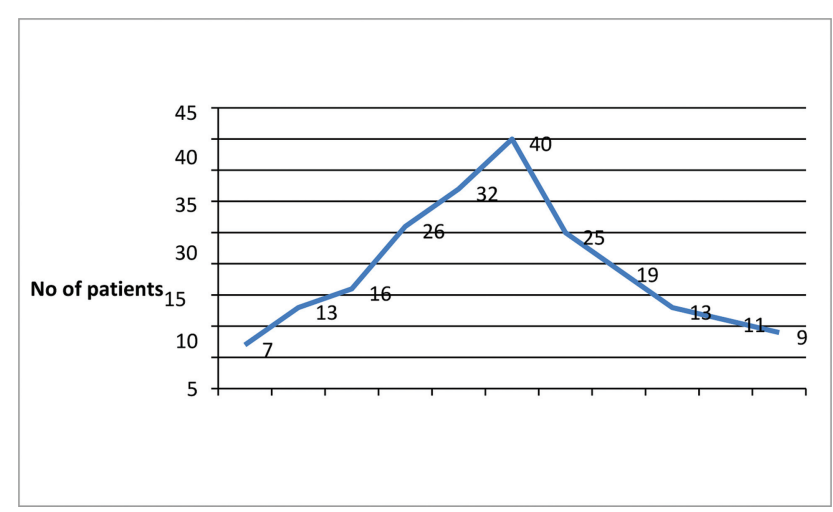

Fig. 1 Age in years.

presented with compartment syndrome and needed immediate fasciotomy. All the patients with type III SC fractures, open SC fractures, and patients with combination injuries reported fall from significant heights as the cause of trauma. Thirteen (9\%) patients had associated nerve injury involving the median nerve in 11 , radial nerve in 1 , and iatrogenic ulnar nerve in 1 . All patients with pink pulse-less hands did well and nobody needed vascular surgeon intervention. Twenty-three patients presented with neglected SC fractures (more than 1 week old) and were managed conservatively. Among these 23 patients, 13 patients presented 3 weeks after the trauma with a complete union in an unacceptable position. All patients with the union in the unacceptable position were planned for corrective osteotomy in the future (-Table 3). 
No of patients

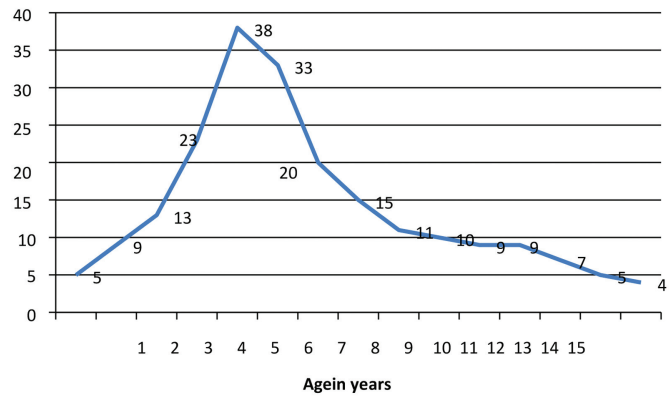

A

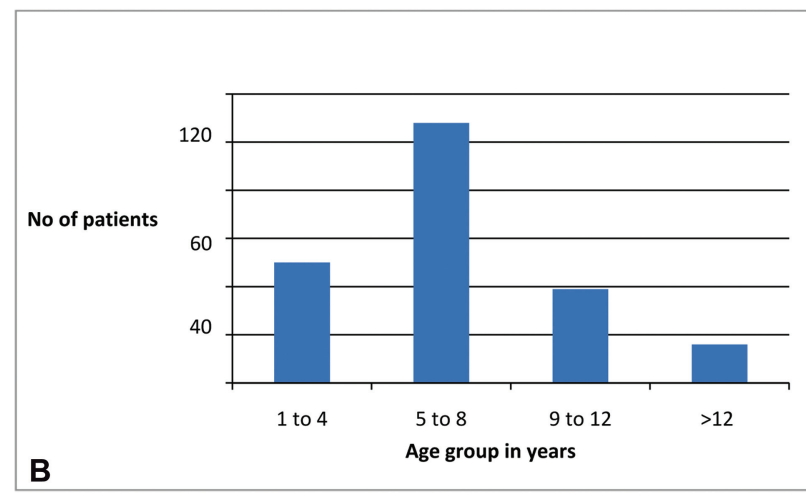

Fig. 2 (A) Age distribution of fractures. (B) Number of patients in different age groups.

The lateral condyle was the second most common fracture in our study. Two patients presented more than 3 weeks late, one with associated injury ulnar nerve palsy and the second patient with an open fracture. Proximal radius fracture was the third most common fracture in our study.

Monteggia fracture was the fourth most common fracture observed. One patient had an open Monteggia fracture. Another patient with a Monteggia fracture presented with compartment syndrome and needed fasciotomy. One patient had posterior interosseous nerve palsy. Two patients with medial epicondyle had ulnar nerve paresthesia. Intercondylar fracture and elbow dislocation were the least common in our study. Distal forearm fracture of the ipsilateral side was the most associated fracture in 7 patients ( - Table 4 ).
Table 3 Parameters of supracondylar fractures

\begin{tabular}{|c|c|}
\hline Parameter & $\begin{array}{l}\text { Number of patients/ } \\
\text { percentage }\end{array}$ \\
\hline Total no of patients & $124 /(58.7)$ \\
\hline \multicolumn{2}{|l|}{ Gender } \\
\hline Male & $70(56)$ \\
\hline Female & $54(44)$ \\
\hline \multicolumn{2}{|l|}{ Laterality } \\
\hline Right & $52(42)$ \\
\hline Left & $73(58)$ \\
\hline \multicolumn{2}{|l|}{ Soft tissue injury } \\
\hline Open fractures & $11(5.2)$ \\
\hline Closed fractures & $200(94.8)$ \\
\hline \multicolumn{2}{|l|}{ Displacement } \\
\hline Extension & $119(96)$ \\
\hline Flexion & $5(4)$ \\
\hline \multicolumn{2}{|l|}{ Gartland classification } \\
\hline Type-1 & $20(16)$ \\
\hline Type-2 & $48(39)$ \\
\hline Type-3 & $56(45)$ \\
\hline \multicolumn{2}{|l|}{ Presentation } \\
\hline Within $48 \mathrm{~h}$ & $43(37)$ \\
\hline $48 \mathrm{~h}$ to $1 \mathrm{wk}$ & $58(46)$ \\
\hline More than $1 \mathrm{wk}$ & $23(17)$ \\
\hline Combination fractures & $11(9)$ \\
\hline Pink pulseless warm hand & $16(7)$ \\
\hline With pale/cold limb & $3(2.4)$ \\
\hline With compartment syndrome & $2(1.6)$ \\
\hline With nerve injury & $13(10)$ \\
\hline
\end{tabular}

\section{Discussion}

This is the first epidemiological study on pediatric elbow fractures from the hilly state of Himachal Pradesh, India, with hilly topography where health care facilities are limited and

Table 2 Mechanism of injury in different age groups

\begin{tabular}{|l|l|l|l|l|l|l|l|}
\hline \multicolumn{2}{|l|}{ Mechanism of trauma } \\
\hline $\begin{array}{l}\text { Age group } \\
\text { (years) } \\
\mathrm{n}\end{array}$ & $\begin{array}{l}\text { Fall on plane } \\
\text { ground (\%) }\end{array}$ & $\begin{array}{l}\text { Fall from } \\
\text { height (\%) }\end{array}$ & $\begin{array}{l}\text { Direct hit/ } \\
\text { trauma (\%) }\end{array}$ & $\begin{array}{l}\text { Sports injury } \\
\mathbf{n}(\%)\end{array}$ & RTA*n (\%) & Unknown (\%) \\
\hline $1-4$ & 50 & $32(64)$ & $11(22)$ & $3(6)$ & $2(4)$ & $2(4)$ & 0 \\
\hline $5-8$ & 100 & $22(22)$ & $64(64)$ & $6(6)$ & $5(5)$ & $2(2)$ & $1(1)$ \\
\hline $9-12$ & 42 & $5(12)$ & $21(50)$ & $2(5)$ & $3(7)$ & $3(7)$ & $1(2)$ \\
\hline$>12$ & 19 & $2(10)$ & $8(42)$ & $7(37)$ & $5(26)$ & $4(21)$ & 0 \\
\hline $\begin{array}{l}\text { No. of patients } \\
(\mathrm{n} / \%)\end{array}$ & $61(29)$ & $104(49)$ & $18(6)$ & $15(7)$ & $11(5)$ & $2(1)$ \\
\hline
\end{tabular}

Abbreviations: n, number of patients. 
Table 4 Features of elbow

\begin{tabular}{|c|c|c|c|c|c|c|c|c|}
\hline \multirow[t]{2}{*}{ Fracture type } & \multirow[t]{2}{*}{$\mathrm{N}(\%)$} & \multirow{2}{*}{$\begin{array}{l}\text { Gender ratio } \\
M / F\end{array}$} & \multirow{2}{*}{$\begin{array}{l}\text { Laterality } \\
\mathrm{R} / \mathrm{L}\end{array}$} & \multicolumn{3}{|c|}{ Presentation } & \multirow[t]{2}{*}{ Complications } & \multirow{2}{*}{$\begin{array}{l}\text { Combination } \\
\text { injury }\end{array}$} \\
\hline & & & & $\begin{array}{l}\text { Early } \\
\text { (within } \\
48 \text { h) }\end{array}$ & $\begin{array}{l}\text { Delayed } \\
\text { (48 h to } \\
7 \mathrm{~d} \text { ) }\end{array}$ & $\begin{array}{l}\text { Late } \\
\text { (after } \\
7 \text { d) }\end{array}$ & & \\
\hline Supracondylar & $\begin{array}{l}124 \\
(58.7)\end{array}$ & 1.81 & 0.7 & 23 & 58 & 43 & 34 & 11 \\
\hline Lateralcondylar & $\begin{array}{l}29 \\
(13.7)\end{array}$ & 1.7 & 0.4 & 9 & 9 & 11 & 2 & 1 \\
\hline Proximal radius & $\begin{array}{l}15 \\
(7.2)\end{array}$ & 1.9 & 0.9 & 7 & 4 & 4 & 0 & 0 \\
\hline Monteggia & $\begin{array}{l}13 \\
(6.1)\end{array}$ & 1.9 & 0.6 & 7 & 4 & 2 & 2 & 1 \\
\hline Olecranon & $\begin{array}{l}11 \\
(5.1)\end{array}$ & 1.7 & 0.4 & 7 & 3 & 1 & 0 & 0 \\
\hline Medial epicondylar & $\begin{array}{l}9 \\
(2.3)\end{array}$ & 1.5 & 0.8 & 3 & 4 & 2 & 1 & 1 \\
\hline Intercondylar & $\begin{array}{l}5 \\
(2.2)\end{array}$ & 1.8 & 0.7 & 3 & 2 & 0 & 0 & 0 \\
\hline Dislocation & $2(0.1)$ & 2 & 0.5 & 1 & 0 & 0 & 0 & 0 \\
\hline
\end{tabular}

Abbreviations: E, early (within 48 h), Delayed (48 h to 7 d); L, late (after 7 d); Lt., left; n, number of patients; Rt., right.

bad road connectivity (roads remain blocked for months during winter).

Fall from a height on an outstretched hand was the most common cause of trauma (in 49\%) in our study, consistent with the findings of Behdad et al. $^{5}$ Only $15 \%$ of the pediatric elbow injuries in our study occurred while playing sports. This could be because of the unavailability of sports grounds in the region because of mountainous topography. Many urban center studies have shown sports as a significant cause of elbow fractures. ${ }^{6}$

A significant seasonal variation was observed in the pattern of pediatric elbow fractures. We observed that $75 \%$ of the fractures were reported in the summer season (April to September) with the maximum number of cases in June. The high number of cases during summer could be because of more outdoor activity during this period. Prolonged winters with very low temperatures and snowfall in this region keep the people limited to their houses and decrease their outdoor activity. Seasonal variations in our study were consistent with the observations by Houshian et al. ${ }^{7}$ Male to female ratio, laterality, and pattern of fractures in different age groups were consistent with the observations of most of the other studies. However, Houshian et al observed elbow fractures more in girls than boys with a boy:girl ratio of $0.8^{7,8}$ (- Table 5).

The supracondylar fracture was the most common and constituted $58 \%$ of all elbow injuries, followed by lateral condyle and proximal radius fracture. The pattern was similar to the findings by Khoshbin et al. ${ }^{9}$ However, the frequency of medial epicondyle, olecranon, and Monteggia fractures was not consistent with this and other studies. ${ }^{10}$ Several studies have shown that the incidence of SC fractures varies from $48 \%$ to $58 \% .{ }^{11-14}$ Okubo et al attributed different trauma mechanisms (varus/valgus impacted force) and different elbow axes in different ethnicities as the cause of varied incidence of elbow fractures. ${ }^{15}$

We observed a higher number of open elbow fractures (5.3\%), a higher number of Gartland type III fractures (45\%), and a higher number of patients (7\%) with combination injuries of ipsilateral upper limb compared with other studies. One of the reasons for this could be that a significant number of low-energy elbow injuries end up with bone practitioners and patients do not visit the hospital. Also,

Table 5 Comparison of findings with other studies

\begin{tabular}{|l|l|l|l|l|l|l|}
\hline Study & No & $\begin{array}{l}\text { Right/left } \\
\text { ratio }\end{array}$ & $\begin{array}{l}\text { Male/female } \\
\text { ratio }\end{array}$ & $\begin{array}{l}\text { Age group with } \\
\text { max involvement }\end{array}$ & $\begin{array}{l}\text { Month with } \\
\text { maximum cases }\end{array}$ & $\begin{array}{l}\text { Month with } \\
\text { minimum cases }\end{array}$ \\
\hline Okubo et $\mathrm{al}^{15}$ & 488 & 0.7 & 1.7 & 6 & July & Jan \\
\hline${\text { Houshian et } \mathrm{al}^{7}}^{7}$ & 355 & 0.7 & 0.8 & 5 & August & December \\
\hline${\text { Landin et } \mathrm{al}^{6}}^{6}$ & 589 & 0.8 & 1.9 & & July & august \\
\hline Behdad et $\mathrm{al}^{5}$ & 300 & 0.7 & 2.6 & $4-8$ & - & - \\
\hline Present study & 211 & 0.6 & 1.8 & 5 & June & January \\
\hline
\end{tabular}


the hilly topography of the region with the mode of trauma from significant heights contributes to it. All patients with open fractures, Gartland type III SC fractures, and all patients with combination injuries had a history of falls from significant heights.

Roposch et al reported $5.3 \%$ of patients with associated injuries in SC fractures in their study. ${ }^{16}$

One of the characteristic features in our study was a high number of patients (19\%) with associated complications at the time of presentation. This was primarily because a significant number of patients (48\%) consulted local bone setters before coming to the hospital. All patients with associated complications had their first contact with bone setters. Vigorous manipulation, forceful massaging after applying some form of oil or herbal products, and tight bandages around the elbow by bone setters cause massive swelling and at times blisters around the elbow. Similar to other developing countries, the culture of native practitioners and bonesetters is still prevalent in rural India., 6,12 Little literature is available on the impact of the culture of native practitioners on orthopaedic injuries in India. It is prevalent in both rural and urban setups, though more common in rural areas.

Native practitioners are almost always from the local community and people usually feel more comfortable visiting them. They charge a minimal amount for services. The orthopaedic services usually are available at higher centers. People have to travel long distances and spend a lot of money to visit the hospitals. Lack of education, poor socioeconomic status, poor health care facilities, and inadequate orthopaedic facilities contribute to the culture of bonesetters in rural India. Being low-energy injuries, a large number of elbow fractures end up with bone setters. In our study, $48 \%$ of patients had first contacted a native practitioner/bone setter and ended up late in hospital, which affected the treatment and outcome.

\section{Novel Insight}

This study highlights the importance of understanding the association of difficult topography with difficult pediatric elbow injuries. We as surgeons should be well versed with these complications and should be ready with correct approaches to treat them. In developing countries such as India, efforts should be made to educate people regarding early reporting to hospitals. This is a pioneer study characterizing the pattern of pediatric trauma presenting in one of the most backward and hilly districts of Chamba, Himachal Pradesh, India.

\section{Already Known Facts}

It is already known that supracondylar and lateral condyle fractures are two of the most common fractures in the pediatric age group

This is one of the first studies on pediatric elbow fractures in India. Fall from height was the most common mechanism of injury and is preventable by simple measures such as sidebars along small link roads around houses and schools, stairs, and rooftops. Being low-energy trauma, a significant number of pediatric elbow injuries get neglected and mis- managed by bonesetters in rural India. People in rural India need to be educated about this.

\section{Informed Consent}

Written informed consent was obtained from all patients and/or families.

\section{Funding}

None.

\section{Conflict of Interest}

None declared.

\section{References}

1 Census of India. 2011. Accessed March 9, 2011 at: http://www. censusindia.gov.in

2 Hussain S, Dar T, Beigh AQ et al. Pattern and epidemiology of pediatric musculoskeletal injuries in Kashmir valley, a retrospective single-center study of 1467 patients. J Pediatr Orthop B 2015; 24(03):230-237

3 Anjum R, Sharma V, Jindal R, Singh TP, Rathee N. Epidemiologic pattern of paediatric supracondylar fractures of humerus in a teaching hospital of rural India: a prospective study of 263 cases. Chin J Traumatol 2017;20(03):158-160

4 Gartland JJ. Management of supracondylar fractures of the humerus in children. Surg Gynecol Obstet 1959;109(02):145-154

5 Behdad A, Behdad S, Hosseinpour M. Pediatric elbow fractures in a major trauma center in iran. Arch Trauma Res 2013;1(04): $172-175$

6 Landin LA, Danielsson LG. Elbow fractures in children. An epidemiological analysis of 589 cases. Acta Orthop Scand 1986;57(04): 309-312

7 Houshian S, Mehdi B, Larsen MS. The epidemiology of elbowfracture in children: analysis of 355 fractures, with special reference to supracondylar humerus fractures. J Orthop Sci 2001;6 (04):312-315

8 Lins RE, Simovitch RW, Waters PM. Pediatric elbow trauma. Orthop Clin North Am 1999;30:119-132

9 Issin A, Kockara N, Oner A, Sahin V. Epidemiologic properties of pediatric fractures in a metropolitan area of Turkey. Medicine (Baltimore) 2015;94(43):e1877

10 Khoshbin A, Leroux T, Wasserstein D, et al. The epidemiology of paediatric supracondylar fracture fixation: a population-based study. Injury 2014;45(04):701-708

11 Cheng JC, Lam TP, Maffulli N. Epidemiological features of supracondylar fractures of the humerus in Chinese children. J Pediatr Orthop B 2001;10(01):63-67

12 Mulpuri K, Hosalkar H, Howard A. AAOS clinical practice guideline:the Treatment of pediatric supracondylar humerus fractures. J Am Acad Orthop Surg 2012;20:328-330

13 Gaudeuille A, Douzima PM, Makolati Sanze B, Mandaba JL. Epidemiology of supracondylar fractures of the humerus in children in Bangui, Central African Republic [article in French]. Med Trop (Mars) 1997;57(01):68-70

14 Biruk LW, Admassie D, Banchiamlak A. Fractures around child's elbow-radiological patterns. East Cent Afr J Surg 2008;13(02):23-28

15 Okubo H, Nakasone M, Kinjo M, Onaka K, Futenma C, Kanaya F. Epidemiology of paediatric elbow fractures: a retrospective multi-centre study of 488 fractures. J Child Orthop 2019;13 (05):516-521

16 Roposch A, Reis M, Molina M, et al. Supracondylar fractures of the humerus associated with ipsilateral forearm fractures in children: a report of forty-seven cases. J Pediatr Orthop 2001;21(03): 307-312 